\title{
Neonatal Injury Alters Sensory Input and Synaptic Plasticity in GABAergic Interneurons of the Adult Mouse Dorsal Horn
}

\author{
Jie Li and $\odot$ Mark L. Baccei \\ Pain Research Center, Department of Anesthesiology, University of Cincinnati College of Medicine, Cincinnati, Ohio 45267
}

\begin{abstract}
Neonatal tissue injury disrupts the balance between primary afferent-evoked excitation and inhibition onto adult spinal projection neurons. However, whether this reflects cell-type-specific alterations at synapses onto ascending projection neurons, or rather is indicative of global changes in synaptic signaling across the mature superficial dorsal horn (SDH), remains unknown. Therefore the present study investigated the effects of neonatal surgical injury on primary afferent synaptic input to adult mouse SDH interneurons using in vitro patch-clamp techniques. Hindpaw incision at postnatal day $(\mathrm{P}) 3$ significantly diminished total primary afferent-evoked glutamatergic drive to adult Gad67-GFP and non-GFP neurons, and reduced their firing in response to sensory input, in both males and females. Early tissue damage also shaped the relative prevalence of monosynaptic A- versus C-fiber-mediated input to mature GABAergic neurons, with an increased prevalence of $\mathrm{A} \beta$ - and $\mathrm{A} \delta$-fiber input observed in neonatally-incised mice compared with naive littermate controls. Paired presynaptic and postsynaptic stimulation at an interval that exclusively produced spike timing-dependent long-term potentiation (t-LTP) in projection neurons predominantly evoked NMDAR-dependent long-term depression in naive Gad67-GFP interneurons. Meanwhile, P3 tissue damage enhanced the likelihood of t-LTP generation at sensory synapses onto the mature GABAergic population, and increased the contribution of $\mathrm{Ca}^{2+}$-permeable AMPARs to the overall glutamatergic response. Collectively, the results indicate that neonatal injury suppresses sensory drive to multiple subpopulations of interneurons in the adult SDH, which likely represents one mechanism contributing to reduced feedforward inhibition of ascending projection neurons, and the priming of developing pain pathways, following early life trauma.
\end{abstract}

Key words: dorsal horn; GABA; incision; neonatal; patch-clamp; spinal cord

Significance Statement

Mounting clinical and preclinical evidence suggests that neonatal tissue damage can result in long-term changes in nociceptive processing within the CNS. Although recent work has demonstrated that early life injury weakens the ability of sensory afferents to evoke feedforward inhibition of adult spinal projection neurons, the underlying circuit mechanisms remain poorly understood. Here we demonstrate that neonatal surgical injury leads to persistent deficits in primary afferent drive to both GABAergic and presumed glutamatergic neurons in the mature superficial dorsal horn (SDH), and modifies activity-dependent plasticity at sensory synapses onto the GABAergic population. The functional denervation of spinal interneurons within the mature SDH may contribute to the "priming" of developing pain pathways following early life injury.

\section{Introduction}

GABAergic and glycinergic synaptic circuits in the spinal dorsal horn are essential for dampening nociceptive transmission in the CNS and thereby diminishing pain sensitivity. Blocking spinal $\mathrm{GABA}_{\mathrm{A}} \mathrm{R}$ and GlyR-mediated signaling evokes robust mechani-

\footnotetext{
Received March 5, 2019; revised Aug. 12, 2019; accepted Aug. 14, 2019.

Author contributions: J.L. and M.L.B. designed research; J.L. performed research; J.L. and M.L.B. analyzed data;

J.L. and M.L.B. wrote the paper.

This work was supported by the National Institutes of Health (NS080889 to M.L.B.).

The authors declare no competing financial interests.

Correspondence should be addressed to Mark L. Baccei at mark.baccei@uc.edu.

https://doi.org/10.1523/JNEUROSCI.0509-19.2019

Copyright $\odot 2019$ the authors
}

cal allodynia and thermal hyperalgesia (Yaksh, 1989; Sivilotti and Woolf, 1994), and the ablation of specific subtypes of spinal inhibitory interneurons also evokes pain hypersensitivity (Duan et al., 2014; Foster et al., 2015; Petitjean et al., 2015). This likely reflects their important role in limiting the excitation of spinal projection neurons (Torsney and MacDermott, 2006) that convey nociceptive signals to the brain (Spike et al., 2003) and are key for the generation of chronic pain (Mantyh et al., 1997; Nichols et al., 1999).

It is also now clear that spinal inhibitory networks are functionally immature at birth (Keller et al., 2001; Bremner and Fitzgerald, 2008). For example, inhibitory synaptic transmission in the neonatal rat superficial dorsal horn $(\mathrm{SDH})$ is dominated by 
$\mathrm{GABA}_{\mathrm{A}} \mathrm{R}$ transmission (Baccei and Fitzgerald, 2004; Koch et al., 2012), which can evoke membrane depolarization during early life due to a weak $\mathrm{Cl}^{-}$extrusion capacity (Cordero-Erausquin et al., 2005). Meanwhile, GlyR-mediated inhibition is slower to emerge during the first postnatal weeks (Baccei and Fitzgerald, 2004), which correlates with significant changes in the expression of GlyR subunits within the dorsal horn (Koch et al., 2012). Given the known importance of neuronal activity in shaping the formation of sensory networks in the dorsal horn (Beggs et al., 2002; Waldenström et al., 2003; Granmo et al., 2008), the slow postnatal maturation of inhibitory synaptic circuits in the region may increase their susceptibility to a persistent reorganization following tissue damage during early life, which commonly occurs during the essential medical care of infants in a neonatal intensive care unit (Simons et al., 2003; Carbajal et al., 2008; Cignacco et al., 2009).

Indeed, our previous work has demonstrated that surgical injury during a critical period of early postnatal development significantly decreases the efficacy of glycinergic transmission in the adult mouse SDH (Li et al., 2013). This was accompanied by a persistent reduction in feedforward $\mathrm{GABA}_{\mathrm{A}} \mathrm{R}$ - and GlyRmediated inhibition of lamina I projection neurons following sensory input to the adult dorsal horn (Li et al., 2015). This deficit in feedforward inhibition could be partially explained by a longterm reduction in the intrinsic membrane excitability of GABAergic SDH interneurons after early tissue damage (Li and Baccei, 2014). Nonetheless, injury-evoked changes in the pattern and strength of primary afferent input to inhibitory interneurons in the SDH could also contribute to the observed alterations in feedforward signaling onto mature projection neurons. Early tissue damage has been shown to strengthen direct sensory inputs to adult projection neurons, as well as increase the prevalence of monosynaptic low-threshold A-fiber input to this population ( $\mathrm{Li}$ et al., 2015). However, the degree to which this might reflect a redirection of developing primary afferent synapses away from inhibitory interneurons and onto ascending projection neurons remains unclear, because little is known about how the connections between sensory fibers and SDH interneurons are influenced by neonatal tissue injury.

The present findings demonstrate that neonatal tissue damage causes prolonged deficits in primary afferent-evoked drive to both inhibitory and putative excitatory interneurons within the adult SDH in both sexes, and persistently modulates activitydependent plasticity at sensory synapses onto mature GABAergic neurons. Collectively, these results provide further evidence that central nociceptive processing during adulthood is strongly influenced by noxious sensory experience during early life.

\section{Materials and Methods}

All experiments adhered to animal welfare guidelines established by the University of Cincinnati Institutional Animal Care and Use Committee.

Hindpaw surgical injury. Female or male Gad-GFP mice [FVB$\operatorname{Tg}$ (GadGFP)4570Swn; The Jackson Laboratory], which express enhanced GFP in GABAergic neurons under the control of the Gad67 promoter (Oliva et al., 2000), were anesthetized with isoflurane (2-3\%) at postnatal day $(\mathrm{P}) 3$ and a small incision made through the skin and underlying muscle of the plantar hindpaw as described previously (Brennan et al., 1996; Li et al., 2013). The skin was immediately closed with 7-0 suture (Ethicon) and the wound fully healed in $\leq 2$ weeks.

Retrograde labeling of spino-parabrachial neurons. In a subset of experiments, $\sim 1$ week before euthanasia, adult $(18-22 \mathrm{~g})$ female mice were anesthetized with a mixture of ketamine $(90 \mathrm{mg} / \mathrm{kg})$ and xylazine $(10$ $\mathrm{mg} / \mathrm{kg}$ ) given via intraperitoneal injection and secured in a stereotaxic apparatus. A single injection of FAST DiI oil ( $100-150 \mathrm{nl} ; 2.5 \mathrm{mg} / \mathrm{ml})$ was administered into the parabrachial nucleus using a Hamilton microsyringe (62RN; $2.5 \mu$ l volume) equipped with a 28 gauge removable needle. Based on an atlas by Paxinos and Franklin (2012), the following stereotaxic coordinates were used (in mm; relative to bregma): 4.8 -5.0 caudal, 1.2-1.4 lateral, and 4.0-4.2 ventral.

Spinal cord slice preparation. At 9-12 weeks of age, female or male Gad-GFP mice were deeply anesthetized with sodium pentobarbital (60 $\mathrm{mg} / \mathrm{kg}$ ) and perfused with ice-cold dissection solution consisting of the following (in mM): 250 sucrose, $2.5 \mathrm{KCl}, 25 \mathrm{NaHCO}_{3}, 1.0 \mathrm{NaH}_{2} \mathrm{PO}_{4}, 6$ $\mathrm{MgCl}_{2}, 0.5 \mathrm{CaCl}_{2}$, and 25 glucose continuously bubbled with $95 \% \mathrm{O}_{2} / 5 \%$ $\mathrm{CO}_{2}$. The lumbar spinal cord was isolated and immersed in low-meltingpoint agarose (3\% in above solution; Life Technologies) and cooled on ice. Parasagittal slices $(350-450 \mu \mathrm{m})$ with the L3-L4 dorsal roots attached (length $7-10 \mathrm{~mm}$ ) were cut using a vibrating microtome (7000smz-2; Campden Instruments). Slices were incubated for 15-20 $\mathrm{min}$ in a recovery solution containing the following (in $\mathrm{mM}$ ): $92 \mathrm{NMDG}$, $2.5 \mathrm{KCl}, 1.2 \mathrm{NaH}_{2} \mathrm{PO}_{4}, 30 \mathrm{NaHCO}_{3}, 20$ HEPES, 25 glucose, $5 \mathrm{Na}$ ascorbate, 2 thiourea, $3 \mathrm{Na}$ pyruvate, $10 \mathrm{MgSO}_{4}$, and $0.5 \mathrm{CaCl}_{2}$ and then allowed to recover further in an oxygenated artificial CSF (aCSF) solution containing the following (in $\mathrm{mM}$ ): $125 \mathrm{NaCl}, 2.5 \mathrm{KCl}, 25 \mathrm{NaHCO}_{3}$, $1.0 \mathrm{NaH}_{2} \mathrm{PO}_{4}, 1.0 \mathrm{MgCl}_{2}, 2.0 \mathrm{CaCl}_{2}$, and 25 glucose for $\geq 1 \mathrm{~h}$ at room temperature.

Patch-clamp recordings. After recovery, slices (with attached dorsal roots) were transferred to a submersion-type recording chamber (RC-22; Warner Instruments) and mounted on the stage of an upright microscope (BX51WI; Olympus). Slices were then perfused at room temperature with oxygenated aCSF at a rate of 3-6 $\mathrm{ml} / \mathrm{min}$.

Patch electrodes were constructed from thin-walled single-filamented borosilicate glass (1.5 mm outer diameter; World Precision Instruments) using a microelectrode puller (P-97; Sutter Instruments). Pipette resistances ranged from 4 to $6 \mathrm{M} \Omega$ and seal resistances were $>1 \mathrm{G} \Omega$. For the majority of experiments, patch electrodes were filled with an intracellular solution containing the following (in $\mathrm{mm}$ ): $130 \mathrm{~K}$-gluconate, $10 \mathrm{KCl}, 10$ HEPES, 10 Na-phosphocreatine, 4 MgATP, and $0.3 \mathrm{Na}_{2}$-GTP, pH 7.2 (295-300 mOsm). For the recordings examining current-voltage ( $I-V)$ relationships of evoked AMPAR currents, patch electrodes were filled with an intracellular solution containing the following (in $\mathrm{mM}$ ): $130 \mathrm{Cs}$ gluconate, $10 \mathrm{CsCl}, 10 \mathrm{HEPES}, 11 \mathrm{EGTA}, 1.0 \mathrm{CaCl}_{2}$, and 2.0 MgATP, $\mathrm{pH}$ 7.2 (305 mOsm).

Whole-cell patch-clamp recordings were obtained from GFP-labeled, or adjacent non-GFP, lamina I-II neurons in the L3/L4 dorsal horn using a MultiClamp 700B amplifier (Molecular Devices). For voltage-clamp experiments, EPSCs were evoked from a holding potential of $-70 \mathrm{mV}$ by electrical stimulation of the dorsal $\operatorname{root}(10 \mu \mathrm{A}-1 \mathrm{~mA}, 100 \mu \mathrm{s})$ delivered via a suction electrode connected to a constant-current stimulator (Master-8, AMPI). The threshold to evoke an EPSC was defined as the current intensity which evoked a measurable EPSC in $\geq 50 \%$ of the trials. The stimulus threshold and onset latency of an evoked EPSC were jointly used to classify the observed synaptic response as mediated by $\mathrm{A} \beta$-fibers, $\mathrm{A} \delta$-fibers, low-threshold C-fibers, or high-threshold C-fibers. EPSCs mediated by $\mathrm{A} \beta$-fibers were classified as monosynaptic based on their ability to follow repetitive stimulation ( 10 stimuli at $1.2 \times$ threshold delivered at $20 \mathrm{~Hz}$ ) with a constant latency and absence of failures. A $\delta$ fiber- and C-fiber-mediated EPSCs were considered monosynaptic if no failures were observed during 2 and $1 \mathrm{~Hz}$ stimulation, respectively.

$I-V$ relationships for evoked AMPAR currents were examined in the presence of $25 \mu \mathrm{M}$ AP5, $10 \mu \mathrm{M}$ gabazine, and $0.5 \mu \mathrm{M}$ strychnine. To quantify the degree of AMPAR current rectification, a rectification index (RI) was calculated as RI $=I \mathrm{hp}_{-40} / I \mathrm{hp}_{+40}$. For current-clamp experiments, action potential discharge was measured from the resting membrane potential in response to dorsal root stimulation of increasing intensity.

Spike timing-dependent plasticity in spinal dorsal horn neurons. Monosynaptic EPSCs were evoked in Gad-GFP neurons (or DiI-labeled lamina I projection neurons) from a holding potential of $-70 \mathrm{mV}$ by stimulation of the attached dorsal root (every $15 \mathrm{~s}$ at an intensity of $1-1.2 \times$ threshold). Following the verification of a stable baseline EPSC amplitude for $\geq 5 \mathrm{~min}$, the same primary afferent stimulus was paired with a postsynaptic action potential evoked by direct intracellular current injection $(150-800 \mathrm{pA} ; 5 \mathrm{~ms})$ at an interval $(\Delta t=-10 \mathrm{~ms})$ that we previously 


\section{Gad-GFP}

A
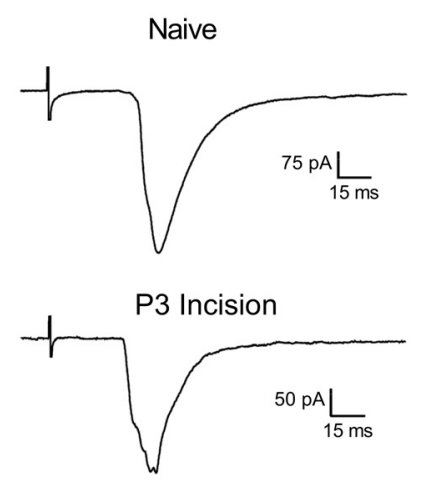

B

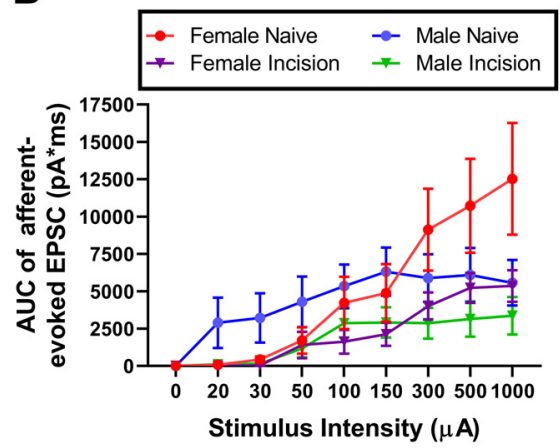

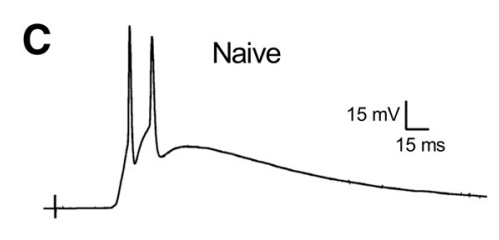

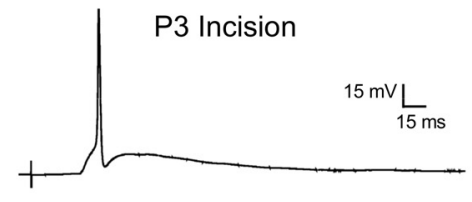

D

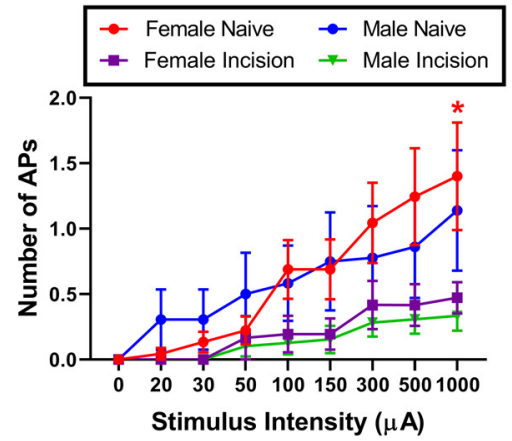

Figure 1. Early surgical injury dampens the total primary afferent-evoked input to GABAergic neurons in the adult spinal dorsal horn. $A$, Representative EPSCs (including both monosynaptic and polysynaptic components) evoked by dorsal root stimulation (500 $\mu \mathrm{A}$ at $100 \mu \mathrm{s}$ ) in Gad-GFP neurons in the adult SDH from naive mice (top) or littermates receiving hindpaw incision at P3 (bottom). $\boldsymbol{B}$, Plot of area under the evoked EPSC (AUC) as a function of stimulus intensity, demonstrating a significant reduction in overall glutamatergic transmission onto adult GABAergic neurons following neonatal incision in both males and females $(n=$ $12-15$ neurons per group; Injury: $F_{(1,48)}=5.175, p=0.027$; Injury $\times$ Sex interaction: $F_{(1,48)}=0.002, p=0.966$; RM three-way ANOVA). C, Example of current-clamp recordings from Gad-GFP neurons sampled in the adult superficial dorsal horn of naive (top) or P3-incised (bottom) mice in response to dorsal root stimulation (500 $\mu \mathrm{A}$ at $100 \mu \mathrm{s})$. D, Surgical incision during early life persistently reduced primary afferent-evoked action potential firing in adult GABAergic neurons independently of $\operatorname{sex}(n=12-15$ neurons per group; Injury: $F_{(1,48)}=6.043, p=0.018,{ }^{*} p<0.05$, Tukey's post-test; Injury $\times$ Sex interaction: $F_{(1,48)}=0.010, p=$ 0.92; RM three-way ANOVA).

demonstrated to evoke maximal spike timing-dependent LTP ( $\mathrm{t}$-LTP) in projection neurons ( $\mathrm{Li}$ and Baccei, 2016). After administration of the pairing protocol (30 pairs of stimuli at $0.2 \mathrm{~Hz}$ ) in the current-clamp mode, neurons were again voltage-clamped at $-70 \mathrm{mV}$ and the primary afferent-evoked EPSCs were recorded for $\geq 25$ min to calculate a mean normalized change in EPSC amplitude (\% baseline). In some experiments, the pairing protocol was administered in the presence of selective antagonists to $\mathrm{Ca}^{2+}$-permeable AMPARs (IEM 1460; $10 \mu \mathrm{M}$ ) or NMDARs (AP5; $25 \mu \mathrm{M}$ ), which were added to the bath solution.

Membrane voltages were adjusted for liquid junction potentials $(\sim-14 \mathrm{mV})$ calculated using JPCalc software (P. Barry, University of New South Wales, Sydney, Australia; modified for Molecular Devices). Currents were filtered at $4-6 \mathrm{kHz}$ through a $-3 \mathrm{~dB}$, four-pole low-pass Bessel filter, digitally sampled at $20 \mathrm{kHz}$, and stored on a personal computer (ICT) using a commercially available data acquisition system (Digidata 1440A with pClamp 10.3 software, Molecular Devices).

Classification of primary afferent input using CAPs. At the completion of each experiment, the dorsal root was cut near the dorsal root entry zone (final length $=6-9 \mathrm{~mm}$ ) and inserted into a second suction electrode connected to the amplifier headstage. Compound action potentials (CAPs) were recorded in response to electrical stimulation of the distal portion of the dorsal root $(0-1 \mathrm{~mA}$ at $100 \mu$ s duration) at room temperature. The stimulus intensities needed to activate $\mathrm{A} \alpha / \mathrm{A} \beta, \mathrm{A} \delta$, and $\mathrm{C}$-fiber CAPs (see Fig. 3A), and the measured conduction velocities, were used to classify the monosynaptic primary afferent-evoked EPSCs recorded earlier. This daily calibration of the stimulus parameters allows one to ac- count for animal-to-animal variability in the diameter of the attached dorsal roots and/or variability in the diameter of different stimulating electrodes.

Experimental design and statistical analysis. The experiments shown in Figure $1, B$ and $D$, involved recordings from 12 to 15 Gad-GFP neurons per group from a total of five female and four male mice, and data were analyzed with a repeated-measure (RM) three-way ANOVA with Stimulus Intensity, Sex and Injury as factors and the Tukey's post-test used for multiple comparisons. For the studies illustrated in Figure 2, $B$ and $D, 12-17$ non-GFP neurons were recorded per group from an additional 8 female mice, and results were pooled with data obtained in female Gad-GFP cells (Fig. 1) and analyzed with a RM three-way ANOVA with Stimulus Intensity, Cell type (i.e., GFP vs non-GFP) and Injury as factors and the Tukey's post-test for multiple comparisons. For the experiment illustrated in Figure $3 C$, data (Naive: $n=68$ cells from 28 female mice; Incision: $n=74$ cells from 28 female mice) were analyzed using the $\chi^{2}$ test. For the measurements of monosynaptic EPSC amplitude (Fig. $3 D$ ), data (Naive: $n=64$ neurons from 28 mice; Incision: $n=71$ neurons from 28 mice) were analyzed using the Mann-Whitney test. For the experiments illustrated in Figure 3E, 9-13 neurons were recorded from three mice in each group, and data were analyzed using RM two-way ANOVA with Bonferroni post-tests for multiple comparisons. For the studies illustrated in Figure $4 F$ characterizing the polarity of spike timing-dependent plasticity (STDP), data (Naive: $n=34$ cells from 15 mice; Incision: $n=33$ cells from 17 mice) were analyzed using the Fisher's exact test. Subsets of these data regarding the magnitude of spike timing-dependent long-term depression (Naive: $n=23$ cells; Incision: $n=9$ cells; Fig. $4 G$ ), t-LTP (Naive: $n=3$ cells; Incision: $n=10$ cells; Fig. $4 H$ ), and overall change in synaptic efficacy (Naive: $n=34$ neurons; Incision: $n=33$ neurons; Fig. $4 I$ ) were analyzed with the Mann-Whitney test. Control experiments confirming the ability of the chosen STDP pairing protocol to induce t-LTP involved recording from seven lamina I projection neurons from five mice.

In addition, the percentage reduction in EPSC amplitude by IEM 1460 (Naive: $n=8$ neurons; Incision: $n=10$ neurons; Fig. $5 B$ ) was compared across groups using the Mann-Whitney test. For the experiment examining the $I-V$ relationships of evoked AMPAR currents as illustrated in Figure $5 D$, data (Naive: $n=12$ neurons from 5 mice; Incision: $n=15$ neurons from 5 mice) were analyzed using RM two-way ANOVA with Sidak's post-tests for multiple comparisons and the calculated rectification indices compared using an unpaired $t$ test (Fig. 5E). For experiments (Fig. $6 B, C$ ) examining the dependence of synaptic plasticity on NMDARs (Naive: $n=8$ cells from 3 mice; Incision: $n=10$ cells from 4 mice) and $\mathrm{Ca}^{2+}$-permeable AMPARs (Naive: $n=8$ cells from 4 mice; Incision: $n=10$ cells from 4 mice), data were analyzed using the Fisher's exact test. All data are expressed as mean \pm SEM and analyzed using Prism 8.0 software (GraphPad Software).

\section{Results}

Neonatal tissue damage dampens primary afferent drive to GABAergic and putative glutamatergic neurons in the adult mouse SDH

To evaluate the degree to which early-life injury modulates the overall efficacy of primary afferent-evoked glutamatergic trans- 
mission onto mature GABAergic interneurons, we obtained patch-clamp recordings from lamina I-II Gad-GFP neurons from adult mice that had undergone unilateral hindpaw incision at P3, compared with naive littermate controls. The area under the total (i.e., monosynaptic and polysynaptic) EPSCs was measured in response to increasing intensities of dorsal root stimulation (Fig. $1 A$ ). In addition, in light of the mounting evidence that the mechanisms governing spinal nociceptive processing and chronic pain can vary between males and females (Sorge et al., 2015; Megat et al., 2018; Moriarty et al., 2019), we also determined the extent to which the persistent effects of early tissue injury depended on sex. Importantly, P3 hindpaw incision significantly dampened primary afferent excitatory drive to Gad-GFP neurons in the mature SDH $\left(n=12-15\right.$ neurons per group; $F_{(1,48)}=$ $5.175, p=0.027$ for Injury; RM three-way ANOVA; Fig. $1 B$ ). Notably, there was no statistically significant interaction between Injury and Sex $\left(F_{(1,48)}=0.002\right.$, $p=0.966)$, suggesting that neonatal incision modulates afferent input to spinal GABAergic neurons similarly in males and females. Furthermore, current-clamp recordings from adult GABAergic neurons (Fig. 1C) demonstrated that neonatal surgical injury significantly reduced primary afferent-evoked action potential discharge in this population compared with naive littermate controls $(n=12-15$ neurons per group, $F_{(1,48)}=6.043, p=$ 0.018 for Injury; RM three-way ANOVA; Fig. $1 D)$ without a significant effect of sex $\left(F_{(1,48)}=0.010, p=0.92\right.$ for interaction between Injury and Sex). Collectively, these data strongly suggest that the ability of sensory afferents to excite inhibitory interneurons in the adult SDH has been persistently weakened by tissue damage during early postnatal development. Given the lack of observed sex differences, the remaining experiments were performed exclusively in SDH neurons from female mice.

To determine the extent to which the reduction in primary afferent drive after neonatal injury is restricted to GABAergic interneurons within the SDH, the above experiments were repeated while recording from non-GFP neurons in laminae I-II, the vast majority of which $(80-90 \%)$ will correspond to glutamatergic neurons (Dougherty et al., 2009; Li and Baccei, 2011). Neonatal hindpaw incision also significantly dampened the total primary afferent-evoked glutamatergic drive to mature non-GFP dorsal horn neurons (Fig. $2 A$ ), because there was a significant overall effect of Injury $\left(n=12-17\right.$ neurons per group; $F_{(1,56)}=$ 6.562, $p=0.013$; RM three-way ANOVA) but no significant interaction between Cell type and Injury $\left(F_{(1,56)}=0.032, p=\right.$ 0.858 ; Fig. $2 B$ ). Similarly, the ability of neonatal incision to reduce afferent-evoked action potential discharge in adult SDH

\section{Non-GFP}

A

Naive

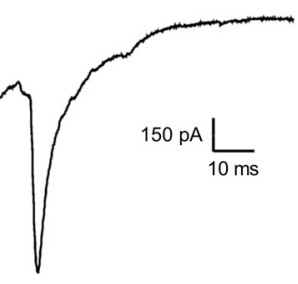

P3 Incision

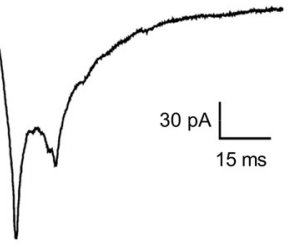

B

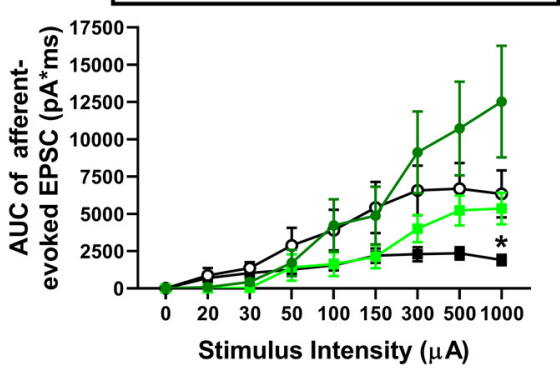

Naive

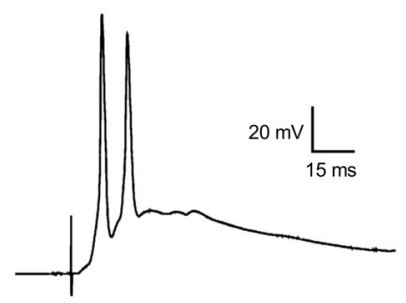

P3 Incision

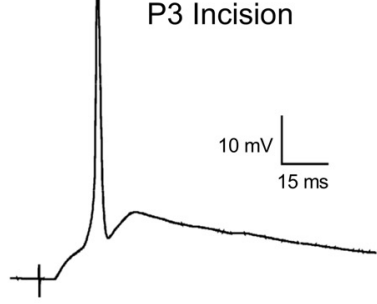

Figure 2. Neonatal hindpaw incision dampens primary afferent drive to putative glutamatergic neurons within the adult dorsal horn. $\boldsymbol{A}$, Representative EPSCS (including both monosynaptic and polysynaptic components) evoked by dorsal root stimulation (bottom). Note the different scale bars on the $y$-axis. B, Plot of area under the evoked EPSC (AUC) as a function of stimulus intensity, demonstrating a significant reduction in overall glutamatergic transmission onto SDH neurons after early-life injury $(n=12-17$ Tukey's post-test for multiple comparisons) but no significant effect of cell type (Cell type $\times$ Injury interaction: $F_{(1,56)}=0.032$, 0.858). Data from the GFP populations correspond to the same data shown for females in Figure $1 B$. C, Example of current( $300 \mu \mathrm{A}$ at $100 \mu$ s). D. Neonatal surgical injury significantly reduced primary afferent-evoked action potential firing 作 regardless of Gad67 expression (Cell type $\times$ Injury interaction: $F_{(1,56)}=0.019, p=0.890$ ). Data from the GFP neurons correspond to the same data shown for females in Figure 10 .

neurons (Fig. 2C) did not differ between the Gad-GFP and non-GFP populations $\left(F_{(1,56)}=0.019, p=0.890\right.$ for the interaction between Cell type and Injury; Fig. $2 D)$, although there was an overall effect of incision on SDH neuronal firing $\left(F_{(1,56)}=9.324, p=0.004\right.$ for Injury $)$. These data indicate that tissue damage during early life evokes a widespread decrease in sensory drive to multiple subtypes of neurons within the adult dorsal horn. Nonetheless, the subsequent experiments focused on the Gad-GFP population to further explore the potential circuit mechanisms underlying the reduced afferent drive to spinal inhibitory interneurons in the aftermath of neonatal injury.

The above injury-evoked decrease in total primary afferent input to mature GABAergic neurons (Fig. 1B) could be explained by changes occurring at afferent synapses onto Gad-GFP neu- 
A
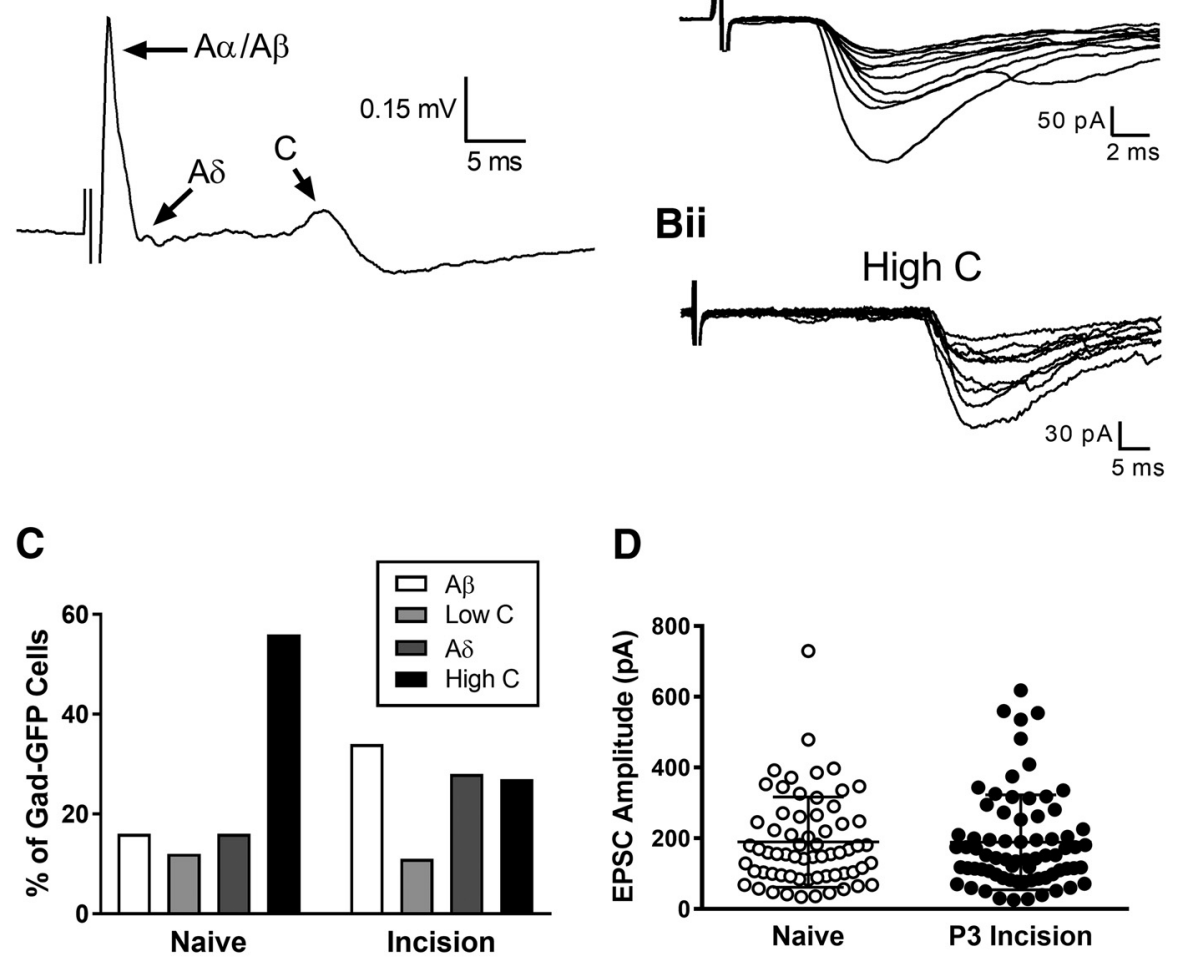

Bii

D

Bi
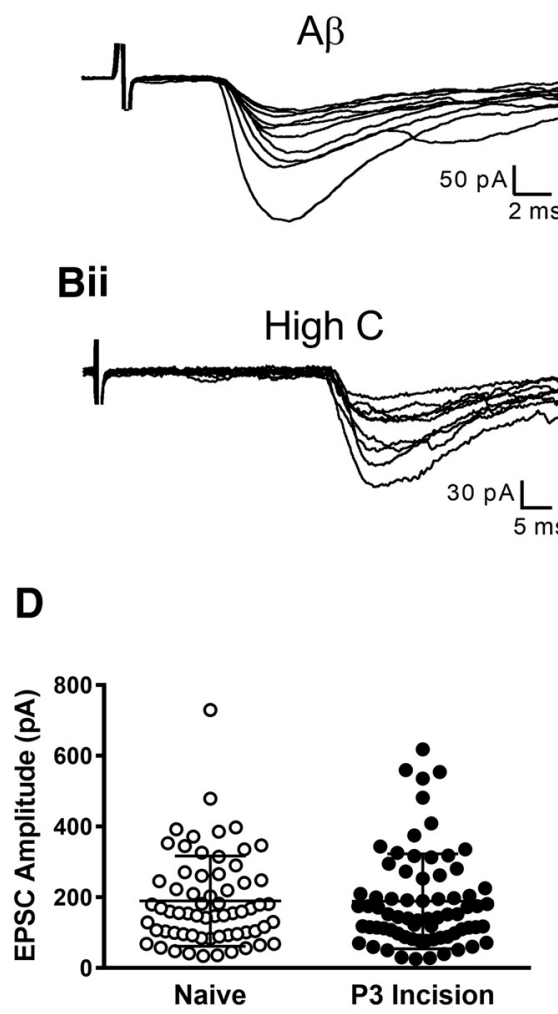

Biii

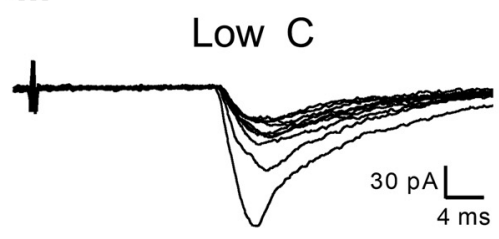

Biv

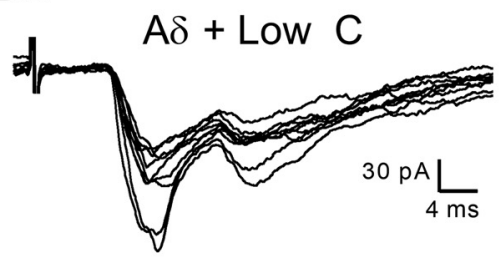

E

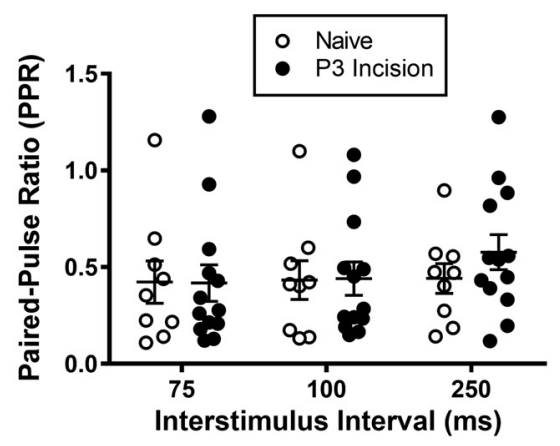

Figure 3. Neonatal surgical injury alters the pattern, but not efficacy, of monosynaptic primary afferent inputs to GABAergic neurons in the adult dorsal horn. $A$, Example of a CAP recorded from an adult mouse dorsal root in response to high-intensity electrical stimulation ( $300 \mu \mathrm{A}, 100 \mu \mathrm{s})$, illustrating $A \alpha / A \beta, A \delta$, and C fiber-mediated components (arrows). $\boldsymbol{B}$, Representative monosynaptic EPSCs observed in Gad-GFP dorsal horn neurons following repetitive dorsal root stimulation, that were classified as being mediated by $A \beta$ fibers $(14 \mu \mathrm{A}$ stimulus at $20 \mathrm{~Hz}$; $\boldsymbol{B i})$, high-threshold C-fibers (200 $\mu \mathrm{A}$ at $2 \mathrm{~Hz}$; Bii), low-threshold C-fibers $(16 \mu \mathrm{A}$ at $2 \mathrm{~Hz}$; Biii) or a combination of A $\delta$-fibers and low-threshold C-fibers (50 $\mu \mathrm{A}$ at $10 \mathrm{~Hz}$; iv). The traces shown in Biii and Biv were obtained from the same Gad-GFP neuron at different stimulus intensities. C, Surgical injury at $P 3$ altered the overall pattern of monosynaptic sensory input to mature Gad-GFP dorsal horn neurons (Naive: $n=68 ; \mathrm{P3}$ Incision: $n=74 ; p=0.003 ; \chi^{2}$ test). $\boldsymbol{D}, \boldsymbol{E}$, Early tissue damage did not change the mean amplitude of monosynaptic primary afferent-evoked EPSCs (Naive: $n=64 ; \mathrm{P} 3$ Incision: $n=71 ; p=0.807$; Mann-Whitney test; $\boldsymbol{D}$ ) or the PPR (Naive: $n=9 ;$ P3 Incision: $n=13 ; F_{(1,40)}=0.127 ; p=0.725$; RM two-way ANOVA; $\boldsymbol{E}$ ). Data from EPS(s evoked by low-threshold and high-threshold primary afferents were pooled for these analyses.

rons, and/or alterations localized elsewhere along the polysynaptic pathways linking sensory neurons to inhibitory interneurons within the SDH. Thus we next investigated the effects of neonatal surgical injury on the pattern and strength of direct sensory input to mature GABAergic SDH neurons. Guided by CAPs recorded from the dorsal root at the end of each experiment (Fig. 3A), monosynaptic EPSCs were classified into distinct primary afferent subtypes (see Materials and Methods) based on their recruitment threshold and onset latency (Fig. 3B). Early tissue injury significantly altered the pattern of monosynaptic primary afferent input to mature GABAergic neurons, with an increased prevalence of $\mathrm{A} \beta$ - and $A \delta$-fiber input and a reduction in the percentage of neurons receiving high-threshold $\mathrm{C}$-fiber input (Naive: $n=68$ neurons sampled; P3 Incision: $n=74 ; p=0.003$; $\chi^{2}$ test; Fig. 3C). However, we observed no significant effects of neonatal tissue damage on the mean amplitude of the afferentevoked monosynaptic EPSCs (Naive: $189.3 \pm 16.0 \mathrm{pA} ; n=64$; P3 Incision: $188.8 \pm 16.0 \mathrm{pA} ; n=71 ; p=0.807$; Mann-Whitney test; Fig. $3 D$ ) or the paired-pulse ratio (PPR) across a range of interstimulus intervals (Naive: mean PPR $=0.43 \pm 0.01, n=9$; P3 Incision: mean PPR $=0.48 \pm 0.05, n=13 ; F_{(1,40)}=0.127 ; p=$ 0.725; RM two-way ANOVA; Fig. 3E).
Early-life surgical injury modulates STDP at sensory synapses onto adult spinal GABAergic neurons

Our previous work has demonstrated that neonatal surgical injury facilitates t-LTP at primary afferent synapses onto adult lamina I projection neurons (Li and Baccei, 2016). Nonetheless, given recent work showing that the same pattern of primary afferent stimulation that evokes LTP in projection neurons results in long-term depression (LTD) in spinal GABAergic interneurons (Kim et al., 2015), it is important to elucidate the potential long-term consequences of early life injury for activity-dependent plasticity at sensory synapses onto inhibitory interneurons in the mature SDH. Therefore, we examined the effects of pairing primary afferent stimulation with postsynaptic action potential discharge (at $\Delta t=-10 \mathrm{~ms}$; see Materials and Methods) on the efficacy of afferent synapses onto Gad-GFP neurons (Fig. 4A). Strikingly, although this STDP protocol uniformly evoked t-LTP in ascending projection neurons ( 7 of 7 neurons sampled; data not shown), the majority of Gad-GFP neurons in lamina I-II of the naive SDH exhibited spike timing-dependent LTD (t-LTD) in response to the same pairing protocol (Fig. $4 B, E$ ), with very few cells exhibiting measurable t-LTP (Fig. $4 C, D, F$, left). The polarity of the observed STDP (i.e., t-LTD vs t-LTP) did not vary significantly across the 
A
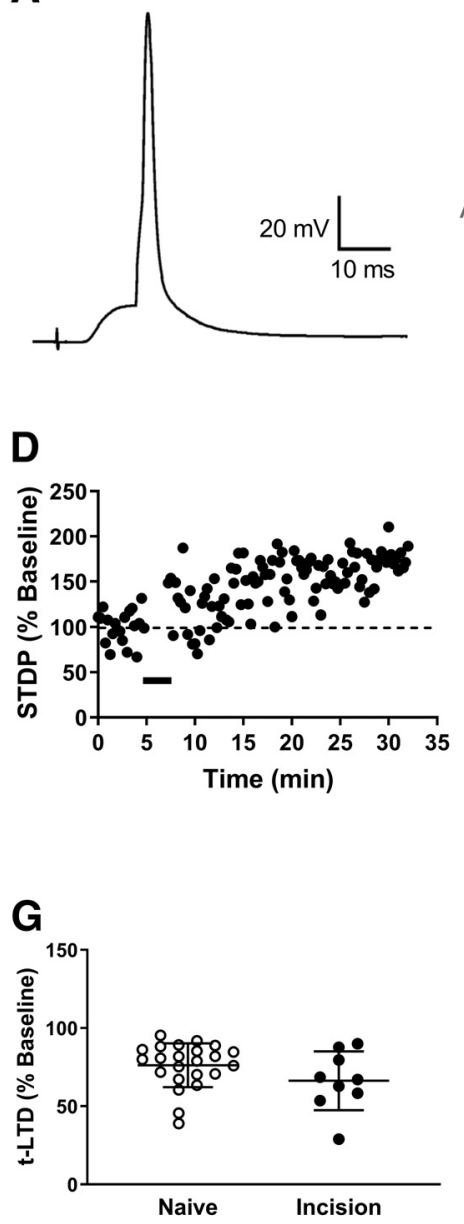

B
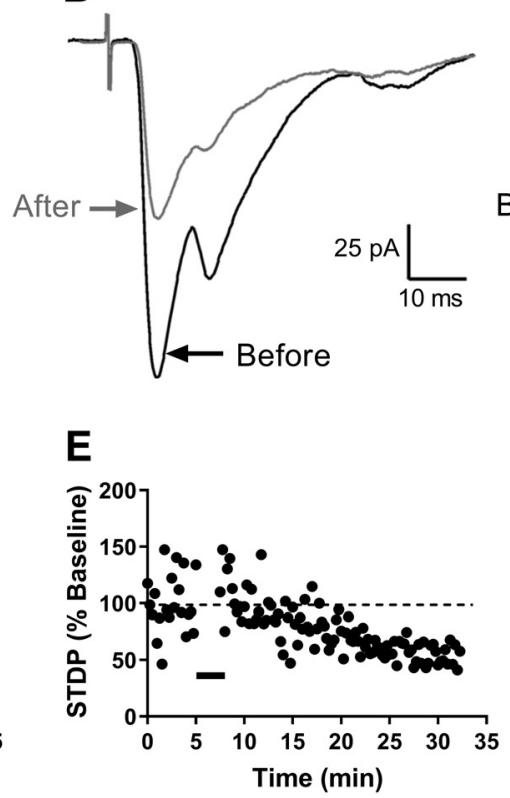

H

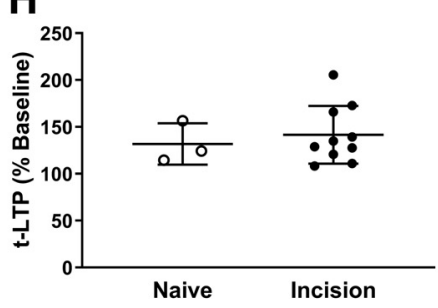

C
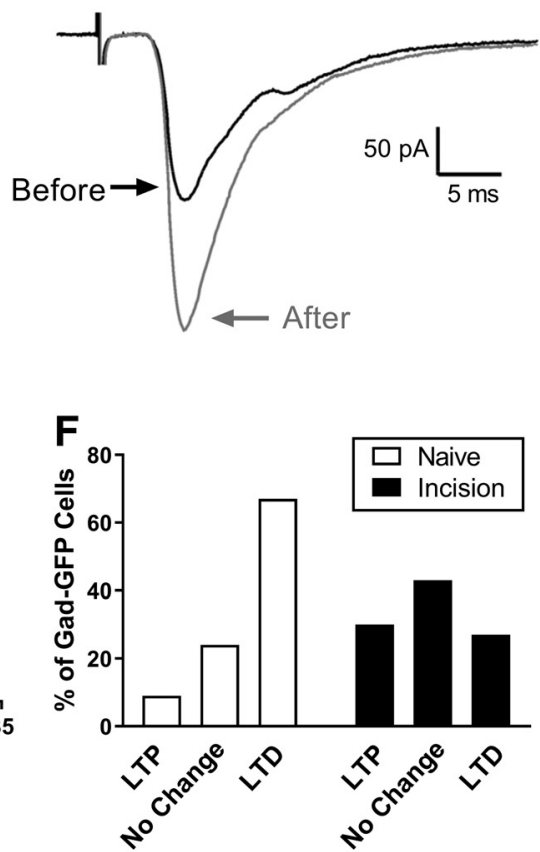

I

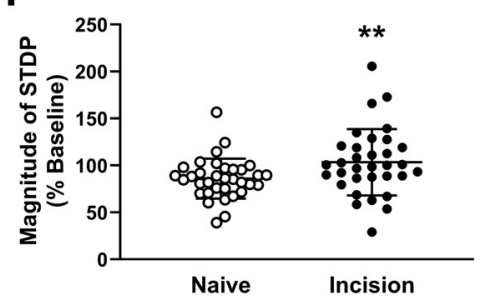

Figure 4. Neonatal injury shifts the balance between spike timing-dependent LTD and LTP at sensory synapses onto GABAergic interneurons in the mature dorsal horn. $\boldsymbol{A}$, Representative current-clamp recording showing the administration of the STDP pairing protocol, in which an action potential was induced in the postsynaptic Gad-GFP neuron at a brief interval ( $\Delta t=-10 \mathrm{~ms}$ ) after the arrival of a primary afferent-evoked EPSP (based on Li and Baccei, 2016). $\boldsymbol{B}$, Example of monosynaptic primary afferent-evoked EPSCs recorded in a Gad-GFP dorsal horn neuron in response to dorsal root stimulation ( $14 \mu \mathrm{A}$ at $100 \mu \mathrm{s}$ ) before (black) and 20 min after (gray) the administration of the STDP pairing protocol ( $30 \mathrm{trials}$ at $0.2 \mathrm{~Hz}$ ), illustrating the induction of t-LTD. C, In another Gad-GFP neuron, the same pairing protocol (with a $60 \mu \mathrm{A}, 100 \mu$ stimulus) enhanced the amplitude of the afferent-evoked EPSC, indicating the existence of t-LTP. $\boldsymbol{D}, \boldsymbol{E}$, Representative plots of STDP (expressed as a percentage of baseline EPSC amplitude before pairing, where $100 \%$ indicates no change in synaptic efficacy) versus time for neurons exhibiting t-LTP (D) or t-LTD (E). Black bar indicates the administration of the pairing protocol. $F$, Surgical injury at $P 3$ significantly reduced the prevalence of t-LTD (Naive: 23 of 34 neurons; $P 3$ Incision: 9 of 33 neurons; $p=0.0014 ;$ Fisher's exact test), whereas it increased the likelihood of t-LTP (Naive: 3 of 34 neurons; $P 3$ Incision: 10 of 33 neurons; $p=0.033$ ), at sensory synapses onto GABAergic neurons of the mature dorsal horn. $G$, $\boldsymbol{H}$, Meanwhile, the average magnitude of t-LTD $(U=66 ; p=0.122 ;$ Mann-Whitney test; $\boldsymbol{G})$ or t-LTP $(U=12 ; p=0.692 ;$ Mann-Whitney test; $\boldsymbol{H})$ was not significantly altered by early-life tissue damage. I, Neonatal hindpaw incision altered the average magnitude of STDP across the overall population of Gad-GFP neurons sampled (Naive: $n=34 ;$ Incision: $n=33 ; U=356 ;{ }^{* *} p=0.0097$; Mann-Whitney test).

different functional classes of primary afferent inputs $(n=9-21$ neurons per group, $p=0.644, \chi^{2}$ test; data not shown), and thus data were pooled to analyze the effects of early-life tissue damage on the plasticity of sensory synapses onto mature GABAergic interneurons.

Importantly, neonatal surgical injury significantly altered STDP at afferent synapses onto GABAergic neurons in the adult $\mathrm{SDH}$, because a significantly smaller percentage of Gad-GFP cells showed t-LTD after P3 hindpaw incision compared with naive littermate controls (Naive: 23 of 34 neurons; P3 Incision: 9 of 33 neurons; $p=0.0014$; Fisher's exact test; Fig. $4 F)$. Nonetheless, among the Gad-GFP neurons that exhibited t-LTD, the magnitude of synaptic depression was not significantly different between the naive and neonatally-injured groups (Naive: $76.2 \pm$ $2.9 \%$ of baseline, $n=23$; P3 Incision: $66.3 \pm 6.3 \%$ of baseline, $n=9 ; U=66 ; p=0.122$; Mann-Whitney test; Fig. $4 G$ ).
Concomitant with the reduced overall prevalence of t-LTD, a greater proportion of mature GABAergic neurons displayed $\mathrm{t}$-LTP in the aftermath of neonatal tissue damage (Naive: 3 of 34 neurons; P3 Incision: 10 of 33 neurons; $p=0.033$; Fisher's exact test; Fig. $4 F$, right). The magnitude of t-LTP at afferent synapses onto mature spinal GABAergic neurons appeared unaffected by early injury (Naive: $131.8 \pm 12.8 \%$ of baseline; P3 Incision: $141.5 \pm 9.8 \%$ of baseline; $U=12 ; p=0.692$; Mann-Whitney test; Fig. $4 H$ ), although a greater sample size is needed to rigorously investigate this issue. Across the overall population of GadGFP neurons sampled (i.e., those exhibiting t-LTP, t-LTD, or no change in synaptic efficacy), neonatal tissue damage significantly influenced the net change in synaptic efficacy evoked by the chosen STDP protocol (Naive: $86.0 \pm 3.7 \%$ of baseline, $n=34$; Incision: $103.4 \pm 6.1 \%$ of baseline, $n=33 ; \mathrm{U}=356 ; p=0.0097$; Mann-Whitney test; Fig. 4I). 
A

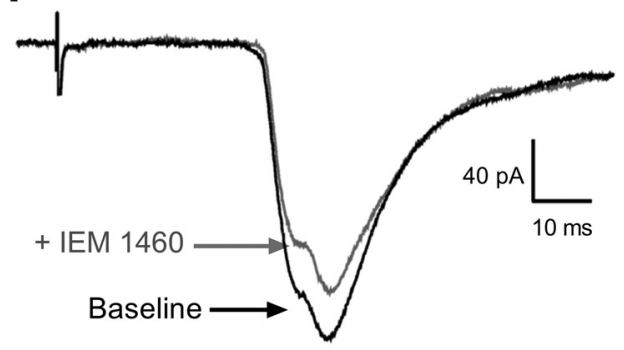

B

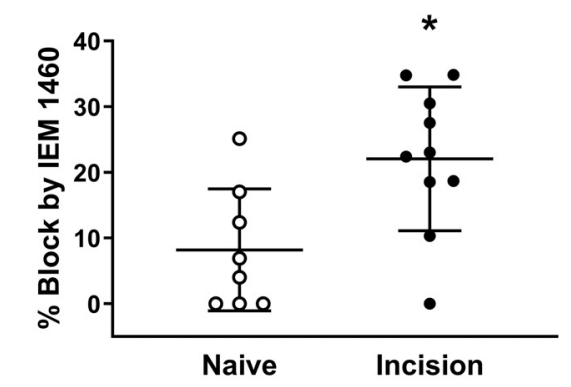

C

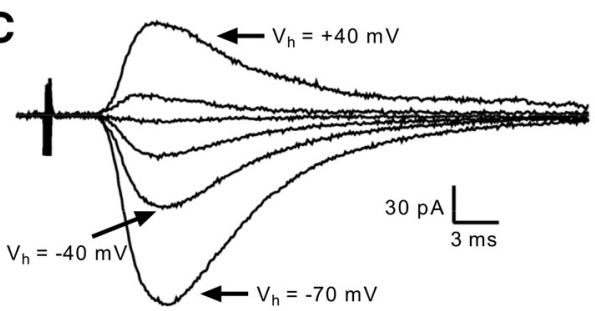

D

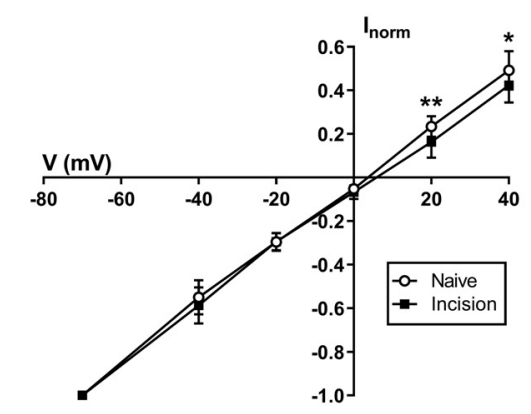

E

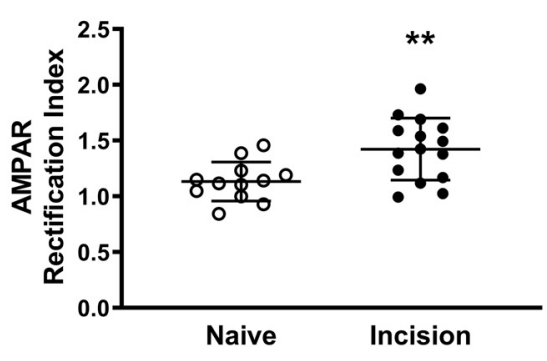

Figure 5. Early surgical incision increases the expression of $\mathrm{Ca}^{2+}$-permeable AMPARs at afferent synapses onto GABAergic interneurons in the adult dorsal horn. $A$, Examples of monosynaptic EPSCs evoked by dorsal root stimulation (150 $\mu$ A at $100 \mu$ s) before (black) and after (gray) the bath application of the selective $\mathrm{Ca}^{2+}$-permeable AMPAR antagonist IEM 1460 (10 $\mu \mathrm{M}) . \boldsymbol{B}$, Hindpaw incision at $\mathrm{P} 3$ resulted in a significant increase in the fraction of the monosynaptic EPSC which was blocked by IEM 1460 (Naive: $n=8$; Incision: $n=10 ; U=13.5 ;{ }^{*} p=$ 0.016; Mann-Whitney test). C, Representative monosynaptic EPSCs evoked by dorsal root stimulation $(16 \mu \mathrm{A}, 100 \mu \mathrm{s})$ from a variety of holding potentials ranging from -70 to $+40 \mathrm{mV}$. D, Plots of normalized EPSC amplitude as a function of holding potential for adult Gad-GFP neurons sampled from naive or neonatally-injured mice, showing an increased degree of inward
Neonatal injury increases the contribution of $\mathrm{Ca}^{2+}$-permeable AMPARs at sensory synapses onto mature GABAergic interneurons

Although prior work suggests that neonatal tissue damage can increase the contribution of $\mathrm{Ca}^{2+}$-permeable AMPARs to primary afferent transmission onto adult lamina I projection neurons ( $\mathrm{Li}$ and Baccei, 2016), the degree to which this also occurs at sensory inputs to inhibitory interneurons within the mature dorsal horn remains unexplored. This issue was investigated using two complementary approaches: (1) measuring the sensitivity of afferent-evoked EPSCs to the selective $\mathrm{Ca}^{2+}$-permeable AMPAR antagonist IEM 1460 (Fig. 5A); and (2) examining the $I-V$ relationships of the evoked AMPAR currents (Fig. 5C,D), because elevated expression of $\mathrm{Ca}^{2+}$-permeable AMPARs is associated with increased inward rectification (Bowie and Mayer, 1995; Donevan and Rogawski, 1995). Neonatal surgical injury significantly increased the sensitivity of the primary afferent-evoked EPSCs to IEM 1460 (Naive: $8.19 \pm 3.28 \%$ inhibition by IEM 1460, $n=8$; Incision: $22.06 \pm 3.46 \%, n=10 ; U=13.5 ; p=$ 0.016; Mann-Whitney test; Fig. 5B). Similarly, the afferentevoked AMPAR currents recorded in mature GABAergic neurons from neonatally-incised mice exhibited more inward rectification compared with naive littermate controls (Naive: $n=$ 12; Incision: $n=15 ; F_{(1,125)}=12.94 ; p=0.0014$; RM two-way ANOVA; Fig. 5D), which was also evidenced by an increased AMPAR rectification index (Naive: $1.13 \pm 0.05, n=12$; Incision: $1.42 \pm 0.07, n=15 ; t=3.12 ; p=0.004$; unpaired $t$ test; Fig. $5 E$ ).

\section{Role of $\mathrm{Ca}^{2+}$-permeable AMPARs and NMDARs in STDP within spinal GABAergic neurons}

Our recent work suggested that early-life injury unmasked a novel role for $\mathrm{Ca}^{2+}$-permeable AMPARs in the generation of t-LTP at sensory synapses onto adult projection neurons, because IEM 1460 prevented t-LTP in neonatally-incised mice but not in naive littermate controls ( $\mathrm{Li}$ and Baccei, 2016). Similarly, the increased prevalence of t-LTP seen in mature GABAergic neurons following neonatal surgical incision was not observed if the pairing protocol was administered in the presence of IEM 1460 (Naive: 1 of 8 cells showing t-LTP; P3 Incision: 1 of 10 cells; $p>$ 0.999; Fisher's exact test; Fig. $6 A, B)$. Interestingly, in naive mice, blocking NMDARs with AP5 significantly reduced the occurrence of t-LTD at sensory synapses onto GABAergic interneurons (aCSF: 23 of 34 neurons; AP5: 1 of 8 neurons; $p=0.013$; Fisher's exact test; Fig. $6 C$, left), with a corresponding increase in the prevalence of t-LTP (aCSF: 3 of 34 neurons; AP5: 4 of 8 neurons; $p=0.017$; Fisher's exact test; Fig. $6 B$, left). These results point to distinct roles for $\mathrm{Ca}^{2+}$-permeable AMPARs and NMDARs in the regulation of activity-dependent synaptic plasticity at primary afferent synapses onto inhibitory interneurons within the SDH network.

\section{Discussion}

Although it is clear that neonatal tissue injuries can persistently alter spinal nociceptive signaling, the striking cellular heterogeneity of the SDH emphasizes the need to better understand how such injuries modulate the function of defined neuronal popula-

$\leftarrow$

rectification at sensory synapses onto Gad-GFP neurons following early-life tissue damage ( $\mathrm{Na}$ ive: $n=12$; Incision: $n=15 ; F_{(1,125)}=12.94 ; p=0.0014$; RM two-way ANOVA; ${ }^{*} p<0.05$, ${ }^{* *} p<0.01$, Sidak's multiple-comparison test). $\boldsymbol{E}$, Neonatal incision also significantly elevated the AMPAR rectification index at these synapses compared with naive littermate controls (Naive: $n=12$; Incision: $n=15 ; t=3.12 ;{ }^{* *} p=0.004$; unpaired $t$ test). 
A

+ IEM 1460

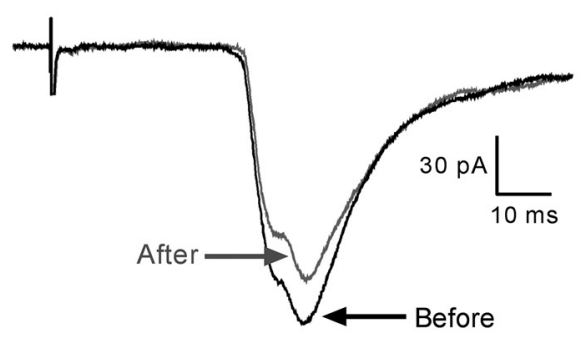

B

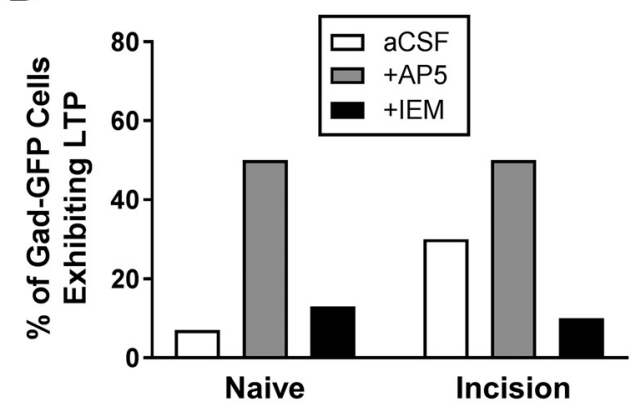

C

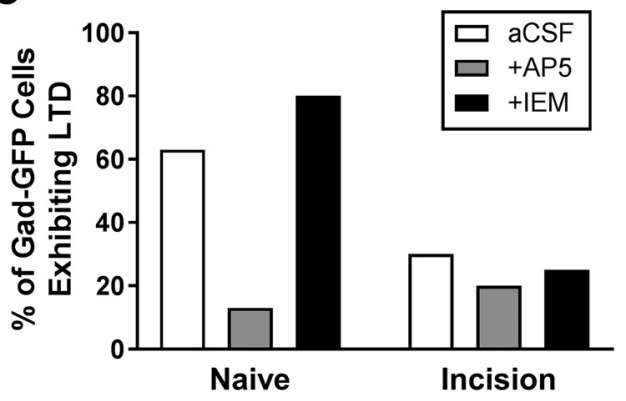

Figure 6. $\mathrm{Ca}^{2+}$-permeable AMPARs and NMDARs regulate the polarity of spike timingdependent plasticity at sensory synapses onto mature spinal GABAergic neurons. $\boldsymbol{A}, \mathrm{Ex}-$ amples of monosynaptic EPSCs evoked by dorsal root stimulation (150 $\mu \mathrm{A}$ at $100 \mu \mathrm{s})$ in an adult Gad-GFP dorsal horn neuron before (black) and after (gray) the administration of the STDP pairing protocol in the continued presence of IEM 1460 in the bath. The displayed EPSCs came from the same neuron depicted in Figure 5 A. B, The increased prevalence oft-LTP normally seen following neonatal tissue damage (white bars) was not observed if the STDP pairing protocol was administered in the presence of IEM 1460 (black bars; $p>0.999$; Fisher's exact test). $C$, Bath application of the selective NMDAR antagonist AP5 (gray bars) significantly decreased the prevalence of t-LTD in Gad-GFP dorsal horn neurons from naive mice ( $p=0.013$; Fisher's exact test).

tions within the region. The present study demonstrates, for the first time, that neonatal surgical incision modifies sensory input to adult spinal GABAergic neurons. This was manifested by an increased prevalence of monosynaptic A-fiber connections, elevated expression of $\mathrm{Ca}^{2+}$-permeable AMPARs, and a facilitation of spike timing-dependent LTP, as previously observed in lamina I projection neurons (PNs) after neonatal injury (Li et al., 2015; Li and Baccei, 2016). However, neonatal tissue damage significantly dampened primary afferent-evoked firing in mature GABAergic interneurons (Fig. 1D), despite enhancing afferent drive to spinoparabrachial neurons (Li et al., 2015), suggesting that a partial functional denervation of spinal inhibitory circuits occurs following noxious sensory experience during early life. Notably, a similar effect was observed in putative glutamatergic interneurons, suggesting that neonatal injury differentially shapes afferent signaling onto local circuit neurons compared with ascending PNs.
The decreased ability of sensory afferents to drive activity in adult GABAergic neurons after neonatal incision likely reflects both a lower intrinsic membrane excitability ( $\mathrm{Li}$ and Baccei, 2014) and a reduction in total glutamatergic input (Fig. 1B). Primary afferent input to this population is also weakened following adult nerve damage, although the underlying mechanisms likely differ. Although adult nerve injury decreases glutamate release from primary afferents onto Gad-GFP neurons (Leitner et al., 2013), we observed no effect of neonatal incision on the efficacy of monosynaptic sensory inputs to mature GABAergic interneurons (Fig. 3). Therefore, the observed decrease in overall primary afferent-evoked glutamatergic transmission after early injury (Fig. 1B) may involve a weaker recruitment of polysynaptic excitatory inputs to GABAergic interneurons. Interestingly, mature glutamatergic interneurons in the SDH also exhibited lower intrinsic firing (Li and Baccei, 2014), and weaker primary afferent input (Fig. 2B), after neonatal tissue damage, which could reduce their contribution to such polysynaptic excitatory pathways. Although the subpopulations of excitatory interneurons (Peirs and Seal, 2016) influenced by neonatal injury remain unidentified, the reduction in glutamatergic drive to $\mathrm{SDH}$ neurons was most pronounced at high intensities of dorsal root stimulation (Figs. $1 B, 2 B)$, thus suggesting a potential effect of early injury on excitatory interneurons receiving extensive C-fiber input. Notably, glutamatergic interneurons expressing somatostatin and calretinin are prevalent in the SDH (Gutierrez-Mecinas et al., 2016, 2019) and strongly innervated by nociceptive afferents (Duan et al., 2014; Smith et al., 2015). Recent strategies to elucidate the transcriptional profile of select subtypes of spinal neurons (Chamessian et al., 2018; Häring et al., 2018) will facilitate the exploration of potential molecular mechanisms underlying the altered excitability of SDH interneurons after early injury.

Neonatal injury may modulate synaptic inhibition in the spinal pain network in a pathway-specific manner, as descending inhibition of SDH neurons is strengthened by early tissue damage (Zhang et al., 2010; Walker et al., 2015). Meanwhile, the decreased sensory drive to mature GABAergic neurons could compromise lateral inhibition within the $\mathrm{SDH}$, and thereby underlie the prolonged expansion of peripheral receptive fields observed in dorsal horn neurons following neonatal injury (Torsney and Fitzgerald, 2003). It may also contribute to the "priming" of spinal nociceptive circuits by early tissue damage, characterized by an exacerbated degree of pain hypersensitivity following repeat injury (Ren et al., 2004; Walker et al., 2009; Beggs et al., 2012). Chemogenetic (Peirs et al., 2015; Christensen et al., 2016) or optogenetic (François et al., 2017; Samineni et al., 2017) strategies could elucidate whether enhancing the activation of GABAergic neurons in the adult SDH can reverse the behavioral manifestations of neonatal priming.

Inhibitory SDH interneurons can be classified into multiple subpopulations based on their expression of neurochemical markers such as galanin, neuronal nitric oxide synthase (nNOS), neuropeptide Y (NPY) and parvalbumin (Tiong et al., 2011), with galanin neurons showing the highest coexpression of the opioid peptide dynorphin (Sardella et al., 2011; Boyle et al., 2017). Different inhibitory circuits can regulate distinct aspects of somatosensory processing, because ablation of mature interneurons from the dynorphin or parvalbumin (PV) lineages produces mechanical allodynia (Duan et al., 2014; Petitjean et al., 2015), whereas lesioning spinal neurons from the NPY lineage evokes chronic itch (Bourane et al., 2015). The Gad-GFP neurons examined in the present study represent a heterogeneous population that includes cells expressing PV and nNOS as well as neurons 
that coexpress glycine (Heinke et al., 2004; Dougherty et al., 2009). Therefore, it will be important to determine which subtypes of spinal GABAergic interneurons are persistently modulated by neonatal tissue injury.

It is tempting to speculate that the weaker afferent drive to mature GABAergic interneurons after neonatal injury contributes to reduced feedforward inhibition of PNs (Li et al., 2015). However, this is based on the assumption that the Gad-GFP neurons, which represent $\sim 63 \%$ of all GABAergic cells in the adult SDH (Dougherty et al., 2009), include the neurons that directly synapse onto PNs. Unfortunately, the subpopulations of GABAergic interneurons that establish monosynaptic connections onto PNs have yet to be fully identified. GABAergic synapses expressing nNOS densely innervate giant lamina I PNs known as Waldeyer cells (Puskár et al., 2001; Polgár et al., 2008; Ganley et al., 2015). Nonetheless, these neurons may represent a fairly small percentage of overall PNs, because they rarely express NK1 receptors (Puskár et al., 2001), whereas $~ 90 \%$ of lamina I PNs exhibit NK1R immunoreactivity (Spike et al., 2003; Cameron et al., 2015). It is important to determine whether neonatal injury reduces the efficacy of inhibitory synapses onto adult PNs, because this would critically influence the overall strength of feedforward inhibition within the SDH network.

In conjunction with our earlier investigation of STDP at sensory synapses onto spino-parabrachial neurons (Li and Baccei, 2016), the current results provide evidence that activitydependent synaptic plasticity can occur in a cell-type-dependent manner within spinal pain circuits. Whereas highly correlated presynaptic and postsynaptic firing predominantly produced t-LTD in adult GABAergic neurons under naive conditions (Fig. 4), this same STDP pairing protocol uniformly evokes t-LTP in lamina I PNs. Notably, both forms of plasticity require NMDAR activation, but only in naive mice (Fig. 6; Li and Baccei, 2016). These findings are highly consistent with those obtained via tetanic stimulation of the dorsal root (Kim et al., 2015). Interestingly, calcium imaging studies suggest that the mechanisms underlying this cell-type-dependent synaptic plasticity may occur downstream of intracellular $\mathrm{Ca}^{2+}$ signaling, because PNs and GABAergic neurons exhibited similar calcium transients in response to primary afferent input (Kim et al., 2015), and may involve the actions of reactive oxygen species (Bittar et al., 2017).

The distinct polarity of afferent-evoked STDP in GABAergic $\mathrm{SDH}$ neurons versus PNs may also reflect differences in G-protein-coupled receptor (GPCR) signaling, because the relative balance between $G_{s}$ and $G_{i}$ signaling clearly influences the direction of STDP in other regions of the CNS, with the activation of $\mathrm{G}_{\mathrm{s}}$-mediated pathways converting t-LTD to t-LTP (Seol et al., 2007; Zhang et al., 2009). While a similar influence of GPCR tone on STDP has yet to be demonstrated in the spinal cord, it is notable that LTP evoked by tetanic stimulation requires the activation of protein kinase A in the SDH (Yang et al., 2004; Ruscheweyh et al., 2011). Because descending pathways from the brain employ a host of GPCRs to modulate the excitability of spinal nociceptive circuits (Millan, 2002), it is also possible that these descending inputs help govern the polarity of activitydependent plasticity at sensory synapses in the SDH, as suggested by prior studies in spinalized rats (Liu et al., 1998).

Neonatal tissue damage significantly increased the prevalence of t-LTP at afferent synapses onto adult GABAergic interneurons while decreasing the likelihood of t-LTD (Fig. 4F). A greater susceptibility to t-LTP at these synapses could partially compensate for the persistent reduction in sensory drive to Gad-GFP neurons after early injury, in an attempt to restore neuronal firing toward a normal range. Such homeostatic responses have been previously described in the mature brain, as manifested by a lower threshold to evoke LTP and a higher magnitude of synaptic potentiation (Félix-Oliveira et al., 2014). Homeostatic plasticity is generally thought to occur globally across all synapses onto a given neuron (Turrigiano et al., 1998; Thiagarajan et al., 2005), although it has been observed at single synapses within the hippocampus (Hou et al., 2008). It would thus be interesting to determine whether other glutamatergic inputs to mature GABAergic interneurons (such as those originating from excitatory SDH interneurons) are also more prone to t-LTP after neonatal insult. It will also be essential to examine additional pairing intervals to gain a more complete picture of how early life injury shapes the timing window for STDP at these synapses.

Collectively, the present results provide clear evidence that the engagement of spinal inhibitory circuits by mature primary afferents is diminished by neonatal tissue damage in both sexes, and thereby identify new potential mechanisms that could link pediatric pain to an increased vulnerability to chronic pain later in life.

\section{References}

Baccei ML, Fitzgerald M (2004) Development of GABAergic and glycinergic transmission in the neonatal rat dorsal horn. J Neurosci 24:4749-4757.

Beggs S, Torsney C, Drew LJ, Fitzgerald M (2002) The postnatal reorganization of primary afferent input and dorsal horn cell receptive fields in the rat spinal cord is an activity-dependent process. Eur J Neurosci 16:12491258.

Beggs S, Currie G, Salter MW, Fitzgerald M, Walker SM (2012) Priming of adult pain responses by neonatal pain experience: maintenance by central neuroimmune activity. Brain 135:404-417.

Bittar A, Jun J, La JH, Wang J, Leem JW, Chung JM (2017) Reactive oxygen species affect spinal cell type-specific synaptic plasticity in a model of neuropathic pain. Pain 158:2137-2146.

Bourane S, Duan B, Koch SC, Dalet A, Britz O, Garcia-Campmany L, Kim E, Cheng L, Ghosh A, Ma Q, Goulding M (2015) Gate control of mechanical itch by a subpopulation of spinal cord interneurons. Science 350:550554.

Bowie D, Mayer ML (1995) Inward rectification of both AMPA and kainate subtype glutamate receptors generated by polyamine-mediated ion channel block. Neuron 15:453-462.

Boyle KA, Gutierrez-Mecinas M, Polgar E, Mooney N, O’Connor E, Furuta T, Watanabe M, Todd AJ (2017) A quantitative study of neurochemically defined populations of inhibitory interneurons in the superficial dorsal horn of the mouse spinal cord. Neuroscience 363:120-133.

Bremner LR, Fitzgerald M (2008) Postnatal tuning of cutaneous inhibitory receptive fields in the rat. J Physiol 586:1529-1537.

Brennan TJ, Vandermeulen EP, Gebhart GF (1996) Characterization of a rat model of incisional pain. Pain 64:493-501.

Cameron D, Polgár E, Gutierrez-Mecinas M, Gomez-Lima M, Watanabe M, Todd AJ (2015) The organisation of spinoparabrachial neurons in the mouse. Pain 156:2061-2071.

Carbajal R, Rousset A, Danan C, Coquery S, Nolent P, Ducrocq S, Saizou C, Lapillonne A, Granier M, Durand P, Lenclen R, Coursol A, Hubert P, de Saint Blanquat L, Boëlle PY, Annequin D, Cimerman P, Anand KJ, Bréart G (2008) Epidemiology and treatment of painful procedures in neonates in intensive care units. JAMA 300:60-70.

Chamessian A, Young M, Qadri Y, Berta T, Ji RR, Van de Ven T (2018) Transcriptional profiling of somatostatin interneurons in the spinal dorsal horn. Sci Rep 8:6809.

Christensen AJ, Iyer SM, François A, Vyas S, Ramakrishnan C, Vesuna S, Deisseroth K, Scherrer G, Delp SL (2016) In vivo interrogation of spinal mechanosensory circuits. Cell Rep 17:1699-1710.

Cignacco E, Hamers J, van Lingen RA, Stoffel L, Büchi S, Müller R, Schutz N, Zimmermann L, Nelle M (2009) Neonatal procedural pain exposure and pain management in ventilated preterm infants during the first 14 days of life. Swiss Med Wkly 139:226-232.

Cordero-Erausquin M, Coull JA, Boudreau D, Rolland M, De Koninck Y (2005) Differential maturation of GABA action and anion reversal po- 
tential in spinal lamina I neurons: impact of chloride extrusion capacity. J Neurosci 25:9613-9623.

Donevan SD, Rogawski MA (1995) Intracellular polyamines mediate inward rectification of $\mathrm{Ca}^{2+}$-permeable alpha-amino-3-hydroxy-5methyl-4-isoxazolepropionic acid receptors. Proc Natl Acad Sci U S A 92:9298-9302.

Dougherty KJ, Sawchuk MA, Hochman S (2009) Phenotypic diversity and expression of GABAergic inhibitory interneurons during postnatal development in lumbar spinal cord of glutamic acid decarboxylase 67-green fluorescent protein mice. Neuroscience 163:909-919.

Duan B, Cheng L, Bourane S, Britz O, Padilla C, Garcia-Campmany L, Krashes M, Knowlton W, Velasquez T, Ren X, Ross S, Lowell BB, Wang Y, Goulding M, Ma Q (2014) Identification of spinal circuits transmitting and gating mechanical pain. Cell 159:1417-1432.

Félix-Oliveira A, Dias RB, Colino-Oliveira M, Rombo DM, Sebastião AM (2014) Homeostatic plasticity induced by brief activity deprivation enhances long-term potentiation in the mature rat hippocampus. J Neurophysiol 112:3012-3022.

Foster E, Wildner H, Tudeau L, Haueter S, Ralvenius WT, Jegen M, Johannssen H, Hosli L, Haenraets K, Ghanem A, Conzelmann KK, Bösl M, Zeilhofer HU (2015) Targeted ablation, silencing, and activation establish glycinergic dorsal horn neurons as key components of a spinal gate for pain and itch. Neuron 85:1289-1304.

François A, Low SA, Sypek EI, Christensen AJ, Sotoudeh C, Beier KT, Ramakrishnan C, Ritola KD, Sharif-Naeini R, Deisseroth K, Delp SL, Malenka RC, Luo L, Hantman AW, Scherrer G (2017) A brainstemspinal cord inhibitory circuit for mechanical pain modulation by GABA and enkephalins. Neuron 93:822-839.e6.

Ganley RP, Iwagaki N, del Rio P, Baseer N, Dickie AC, Boyle KA, Polgár E, Watanabe M, Abraira VE, Zimmerman A, Riddell JS, Todd AJ (2015) Inhibitory interneurons that express GFP in the PrP-GFP mouse spinal cord are morphologically heterogeneous, innervated by several classes of primary afferent and include lamina I projection neurons among their postsynaptic targets. J Neurosci 35:7626-7642.

Granmo M, Petersson P, Schouenborg J (2008) Action-based body maps in the spinal cord emerge from a transitory floating organization. J Neurosci 28:5494-5503.

Gutierrez-Mecinas M, Furuta T, Watanabe M, Todd AJ (2016) A quantitative study of neurochemically defined excitatory interneuron populations in laminae I-III of the mouse spinal cord. Mol Pain 12: 1744806916629065.

Gutierrez-Mecinas M, Davis O, Polgár E, Shahzad M, Navarro-Batista K, Furuta T, Watanabe M, Hughes DI, Todd AJ (2019) Expression of calretinin among different neurochemical classes of interneuron in the superficial dorsal horn of the mouse spinal cord. Neuroscience 398:171181.

Häring M, Zeisel A, Hochgerner H, Rinwa P, Jakobsson JET, Lönnerberg P, La Manno G, Sharma N, Borgius L, Kiehn O, Lagerström MC, Linnarsson S, Ernfors P (2018) Neuronal atlas of the dorsal horn defines its architecture and links sensory input to transcriptional cell types. Nat Neurosci $21: 869-880$.

Heinke B, Ruscheweyh R, Forsthuber L, Wunderbaldinger G, Sandkühler J (2004) Physiological, neurochemical and morphological properties of a subgroup of GABAergic spinal lamina II neurones identified by expression of green fluorescent protein in mice. J Physiol 560:249-266.

Hou Q, Zhang D, Jarzylo L, Huganir RL, Man HY (2008) Homeostatic regulation of AMPA receptor expression at single hippocampal synapses. Proc Natl Acad Sci U S A 105:775-780.

Keller AF, Coull JA, Chery N, Poisbeau P, De Koninck Y (2001) Regionspecific developmental specialization of GABA-glycine cosynapses in laminas I-II of the rat spinal dorsal horn. J Neurosci 21:7871-7880.

Kim HY, Jun J, Wang J, Bittar A, Chung K, Chung JM (2015) Induction of long-term potentiation and long-term depression is cell-type specific in the spinal cord. Pain 156:618-625.

Koch SC, Tochiki KK, Hirschberg S, Fitzgerald M (2012) C-fiber activitydependent maturation of glycinergic inhibition in the spinal dorsal horn of the postnatal rat. Proc Natl Acad Sci U S A 109:12201-12206.

Leitner J, Westerholz S, Heinke B, Forsthuber L, Wunderbaldinger G, Jäger T, Gruber-Schoffnegger D, Braun K, Sandkühler J (2013) Impaired excitatory drive to spinal GABAergic neurons of neuropathic mice. PLoS One 8:e73370.

Li J, Baccei ML (2011) Neonatal tissue damage facilitates nociceptive synap- tic input to the developing superficial dorsal horn via NGF-dependent mechanisms. Pain 152:1846-1855.

Li J, Baccei ML (2014) Neonatal tissue injury reduces the intrinsic excitability of adult mouse superficial dorsal horn neurons. Neuroscience 256:392-402.

Li J, Baccei ML (2016) Neonatal tissue damage promotes spike timingdependent synaptic long-term potentiation in adult spinal projection neurons. J Neurosci 36:5405-5416.

Li J, Blankenship ML, Baccei ML (2013) Deficits in glycinergic inhibition within adult spinal nociceptive circuits after neonatal tissue damage. Pain 154:1129-1139.

Li J, Kritzer E, Craig PE, Baccei ML (2015) Aberrant synaptic integration in adult lamina I projection neurons following neonatal tissue damage. J Neurosci 35:2438-2451.

Liu XG, Morton CR, Azkue JJ, Zimmermann M, Sandkühler J (1998) Longterm depression of C-fibre-evoked spinal field potentials by stimulation of primary afferent A delta-fibres in the adult rat. Eur J Neurosci 10: 3069-3075.

Mantyh PW, Rogers SD, Honore P, Allen BJ, Ghilardi JR, Li J, Daughters RS, Lappi DA, Wiley RG, Simone DA (1997) Inhibition of hyperalgesia by ablation of lamina I spinal neurons expressing the substance P receptor. Science 278:275-279.

Megat S, Shiers S, Moy JK, Barragan-Iglesias P, Pradhan G, Seal RP, Dussor G, Price TJ (2018) A critical role for dopamine D5 receptors in pain chronicity in male mice. J Neurosci 38:379-397.

Millan MJ (2002) Descending control of pain. Prog Neurobiol 66:355-474.

Moriarty O, Tu Y, Sengar AS, Salter MW, Beggs S, Walker SM (2019) Priming of adult incision response by early-life injury: neonatal microglial inhibition has persistent but sexually dimorphic effects in adult rats. J Neurosci 39:3081-3093.

Nichols ML, Allen BJ, Rogers SD, Ghilardi JR, Honore P, Luger NM, Finke MP, Li J, Lappi DA, Simone DA, Mantyh PW (1999) Transmission of chronic nociception by spinal neurons expressing the substance $P$ receptor. Science 286:1558-1561.

Oliva AA Jr, Jiang M, Lam T, Smith KL, Swann JW (2000) Novel hippocampal interneuronal subtypes identified using transgenic mice that express green fluorescent protein in GABAergic interneurons. J Neurosci 20: $3354-3368$.

Paxinos G, Franklin KBJ (2012) The mouse brain in stereotaxic coordinates, 4th edition. London: Academic Press.

Peirs C, Seal RP (2016) Neural circuits for pain: recent advances and current views. Science 354:578-584.

Peirs C, Williams SP, Zhao X, Walsh CE, Gedeon JY, Cagle NE, Goldring AC, Hioki H, Liu Z, Marell PS, Seal RP (2015) Dorsal horn circuits for persistent mechanical pain. Neuron 87:797-812.

Petitjean H, Pawlowski SA, Fraine SL, Sharif B, Hamad D, Fatima T, Berg J, Brown CM, Jan LY, Ribeiro-da-Silva A, Braz JM, Basbaum AI, SharifNaeini R (2015) Dorsal horn parvalbumin neurons are gate-keepers of touch-evoked pain after nerve injury. Cell Rep 13:1246-1257.

Polgár E, Al-Khater KM, Shehab S, Watanabe M, Todd AJ (2008) Large projection neurons in lamina I of the rat spinal cord that lack the neurokinin 1 receptor are densely innervated by VGLUT2-containing axons and possess GluR4-containing AMPA receptors. J Neurosci 28:1315013160.

Puskár Z, Polgár E, Todd AJ (2001) A population of large lamina I projection neurons with selective inhibitory input in rat spinal cord. Neuroscience 102:167-176.

Ren K, Anseloni V, Zou SP, Wade EB, Novikova SI, Ennis M, Traub RJ, Gold MS, Dubner R, Lidow MS (2004) Characterization of basal and reinflammation-associated long-term alteration in pain responsivity following short-lasting neonatal local inflammatory insult. Pain 110:588596.

Ruscheweyh R, Wilder-Smith O, Drdla R, Liu XG, Sandkühler J (2011) Long-term potentiation in spinal nociceptive pathways as a novel target for pain therapy. Mol Pain 7:20.

Samineni VK, Yoon J, Crawford KE, Jeong YR, McKenzie KC, Shin G, Xie Z, Sundaram SS, Li Y, Yang MY, Kim J, Wu D, Xue Y, Feng X, Huang Y, Mickle AD, Banks A, Ha JS, Golden JP, Rogers JA, Gereau RW 4th (2017) Fully implantable, battery-free wireless optoelectronic devices for spinal optogenetics. Pain 158:2108-2116.

Sardella TC, Polgar E, Garzillo F, Furuta T, Kaneko T, Watanabe M, Todd AJ 
(2011) Dynorphin is expressed primarily by GABAergic neurons that contain galanin in the rat dorsal horn. Mol Pain 7:76.

Seol GH, Ziburkus J, Huang S, Song L, Kim IT, Takamiya K, Huganir RL, Lee HK, Kirkwood A (2007) Neuromodulators control the polarity of spiketiming-dependent synaptic plasticity. Neuron 55:919-929.

Simons SH, van Dijk M, Anand KS, Roofthooft D, van Lingen RA, Tibboel D (2003) Do we still hurt newborn babies? A prospective study of procedural pain and analgesia in neonates. Arch Pediatr Adolesc Med 157: 1058-1064.

Sivilotti L, Woolf CJ (1994) The contribution of GABAA and glycine receptors to central sensitization: disinhibition and touch-evoked allodynia in the spinal cord. J Neurophysiol 72:169-179.

Smith KM, Boyle KA, Madden JF, Dickinson SA, Jobling P, Callister RJ, Hughes DI, Graham BA (2015) Functional heterogeneity of calretininexpressing neurons in the mouse superficial dorsal horn: implications for spinal pain processing. J Physiol 593:4319-4339.

Sorge RE, Mapplebeck JC, Rosen S, Beggs S, Taves S, Alexander JK, Martin LJ, Austin JS, Sotocinal SG, Chen D, Yang M, Shi XQ, Huang H, Pillon NJ, Bilan PJ, Tu Y, Klip A, Ji RR, Zhang J, Salter MW, Mogil JS (2015) Different immune cells mediate mechanical pain hypersensitivity in male and female mice. Nat Neurosci 18:1081-1083.

Spike RC, Puskár Z, Andrew D, Todd AJ (2003) A quantitative and morphological study of projection neurons in lamina I of the rat lumbar spinal cord. Eur J Neurosci 18:2433-2448.

Thiagarajan TC, Lindskog M, Tsien RW (2005) Adaptation to synaptic inactivity in hippocampal neurons. Neuron 47:725-737.

Tiong SY, Polgár E, van Kralingen JC, Watanabe M, Todd AJ (2011) Galanin-immunoreactivity identifies a distinct population of inhibitory interneurons in laminae I-III of the rat spinal cord. Mol Pain 7:36.

Torsney C, Fitzgerald M (2003) Spinal dorsal horn cell receptive field size is increased in adult rats following neonatal hindpaw skin injury. J Physiol 550:255-261.

Torsney C, MacDermott AB (2006) Disinhibition opens the gate to pathological pain signaling in superficial neurokinin 1 receptor-expressing neurons in rat spinal cord. J Neurosci 26:1833-1843.

Turrigiano GG, Leslie KR, Desai NS, Rutherford LC, Nelson SB (1998) Activity-dependent scaling of quantal amplitude in neocortical neurons. Nature 391:892-896.

Waldenström A, Thelin J, Thimansson E, Levinsson A, Schouenborg J (2003) Developmental learning in a pain-related system: evidence for a cross-modality mechanism. J Neurosci 23:7719-7725.

Walker SM, Tochiki KK, Fitzgerald M (2009) Hindpaw incision in early life increases the hyperalgesic response to repeat surgical injury: critical period and dependence on initial afferent activity. Pain 147:99-106.

Walker SM, Fitzgerald M, Hathway GJ (2015) Surgical injury in the neonatal rat alters the adult pattern of descending modulation from the rostroventral medulla. Anesthesiology 122:1391-1400.

Yaksh TL (1989) Behavioral and autonomic correlates of the tactile evoked allodynia produced by spinal glycine inhibition: effects of modulatory receptor systems and excitatory amino acid antagonists. Pain 37:111-123.

Yang HW, Hu XD, Zhang HM, Xin WJ, Li MT, Zhang T, Zhou LJ, Liu XG (2004) Roles of CaMKII, PKA, and PKC in the induction and maintenance of LTP of C-fiber-evoked field potentials in rat spinal dorsal horn. J Neurophysiol 91:1122-1133.

Zhang JC, Lau PM, Bi GQ (2009) Gain in sensitivity and loss in temporal contrast of STDP by dopaminergic modulation at hippocampal synapses. Proc Natl Acad Sci U S A 106:13028-13033.

Zhang YH, Wang XM, Ennis M (2010) Effects of neonatal inflammation on descending modulation from the rostroventromedial medulla. Brain Res Bull 83:16-22. 